\title{
Piperacillin-tazobactam as alternative to carbapenems for ICU patients
}

\author{
Benoit Pilmis ${ }^{1,2}$, Vincent Jullien ${ }^{3,4}$, Alexis Tabah ${ }^{5,6}$, Jean-Ralph Zahar ${ }^{7,8^{*}}$ and Christian Brun-Buisson ${ }^{9}$
}

\begin{abstract}
Several studies suggest that alternatives to carbapenems, and particulary beta-lactam/beta-lactamase inhibitor combinations, can be used for therapy of extended-spectrum beta-lactamase-producing Enterobacteriaceae (ESBLPE)-related infections in non-ICU patients. Little is known concerning ICU patients in whom achieving the desired plasmatic pharmacokinetic/pharmacodynamic (PK/PD) target may be difficult. Also, in vitro susceptibility to betalactamase inhibitors might not translate into clinical efficacy. We reviewed the recent clinical studies examining the use of BL/BLI as alternatives to carbapenems for therapy of bloodstream infection, PK/PD data and discuss potential ecological benefit from avoiding the use of carbapenems. With the lack of prospective randomized studies, treating ICU patients with ESBL-PE-related infections using piperacillin-tazobactam should be done with caution. Current data suggest that BL/BLI empirical use should be avoided for therapy of ESBL-PE-related infection. Also, definitive therapy should be reserved to patients in clinical stable condition, after microbial documentation and results of susceptibility tests. Optimization of administration and higher dosage should be used in order to reach pharmacological targets.
\end{abstract}

Keywords: Carbapenems, ESBL, Alternatives, Ecological consequences, Outcome

\section{Introduction}

Since the 1980s, extended-spectrum beta-lactamase (ESBL)-producing Enterobacteriaceae (ESBL-PE) have been spreading worldwide $[1,2]$. Several reports underline the concomitant increasing use of carbapenems $[3,4]$. Indeed, the recently published 2015 ESAC report noted a threefold increased use of carbapenems between 2010 and 2014 [5]. This induces a selective pressure for carbapenem-resistant isolates, and recent data suggest that even a brief exposure to carbapenems increases the risk of colonization with carbapenem-resistant bacteria (CRB) in intensive care unit patients [6].

To reduce the ecological risk associated with the increased consumption of last-line antibiotics, two main strategies are available: (1) searching for alternative treatments for ESBL-PE-related infections and (2) antimicrobial de-escalation (ADE). Therefore, the use

\footnotetext{
*Correspondence: jeanralph.zahar@aphp.fr

${ }^{7}$ Département de Microbiologie Clinique, Unité de Contrôle et de Prévention du risque Infectieux, Groupe Hospitalier Paris Seine Saint-Denis, AP-HP, CHU Avicenne, 125 rue de Stalingrad, 9300 Bobigny, France

Full list of author information is available at the end of the article
}

of alternatives to carbapenems such as cephamycins, piperacillin-tazobactam and others for the treatment of ESBL-PE infections should be investigated. A recent systematic review, including two randomized controlled trials and 12 cohort studies, highlighted that the effects of ADE on antimicrobial resistance have not been properly studied [7]. However, this strategy is largely promoted by several scientific societies and specifically in critically ill patients $[8,9]$. Indeed, for severely ill patients, international guidelines recommend the use of broad-spectrum antibiotics as first-line therapy to minimize the risk of inadequate initial antimicrobial treatment, and suggest streamlining initial antibiotic therapy and narrowing the spectrum whenever possible once the pathogen(s) are identified [10].

Until recently, the common rule is to treat infections caused by ESBL-producing organism with carbapenems. However, ESBLs are inhibited in vitro by beta-lactamase inhibitors and several studies have suggested the use of $\beta$-lactam/ $\beta$-lactamase inhibitor combinations (BL/ BLIs) such as piperacillin-tazobactam as a carbapenemsparing strategy for the treatment of ESBL-PE-related infections [11-13]. The recent EUCAST and CLSI [14, 
15] guidelines include BL/BLIs and other beta-lactams (cefepime, third generation cephalosporins, temocillin, cefoxitin) as treatment options for infections caused by ESBL-producing organisms. For a long time, AST categorization was based not only on MIC and zone diameter measurements but also on the detection of individual resistance mechanisms, i.e., interpretative reading. Even if in vitro results indicated susceptibility to a drug, the reported category was edited to "resistant" if the presence of a resistance mechanism was confirmed, e.g., in the case of extended-spectrum beta-lactamases (ESBLs). To limit the consumption of carbapenems, CLSI and EUCAST recently abandoned editing of AST reports based on the detection of ESBLs.

While several studies are conducted in ICU, data remain scarce concerning other beta-lactams in nonICU- $[16,17]$ and ICU-infected [18-21] patients. Therefore, only BL/BLIs such as piperacillin-tazobactam (Pip-Taz) could be used in ICU patients, but there are concerns that: (1) no randomized controlled trials compared specifically carbapenems to Pip-Taz for the treatment of ESBL-PE-related infections [22]; (2) in vitro susceptibility to $\beta$-lactamase inhibitors might not predict clinical efficacy; and (3) the success of BL/BLIs depends on pharmacokinetic-pharmacodynamic target attainment, which current dosing recommendations may not guarantee. Therefore, alternatives are seldom used in clinical practice for treating serious infections caused by ESBL-PE.

In critically ill patients, pharmacokinetics of beta-lactam antibiotics differs from healthy volunteers. Lower than expected concentrations have been reported for meropenem, piperacillin, amoxicillin, as well as for cephalosporins [23-26]. Besides, the risk of treatment failure may be exacerbated when using antibiotics exposed to the inoculum effect [27], as are most beta-lactams.

This narrative review, based on microbiological, pharmacodynamics, clinical and ecological data, describes the available evidence for the use of Pip-Taz as an alternative to carbapenems in critically ill patients and to provide some guidance to prescribers for using these drugs when treating infections caused by ESBL-PE.

\section{Methods}

\section{Literature search}

A literature search was performed via PubMed, including all records from 1990 through April 2016. The following search pattern was applied: (ESBL OR extended-spectrum $\beta$-lactamases) AND (infection) AND (cefepime OR cefoxitine OR cephamycins OR flomoxef OR BL/BLI OR Piperacillin-tazobactam OR Carbapenems OR temocillin OR alternatives). Reference lists were cross-checked to identify further publications for possible inclusion. We restricted inclusion to studies published in the English, Spanish and French languages.

\section{Selection criteria}

We screened and included studies in three categories according to the following criteria: (1) pharmacokinetics and pharmacodynamics studies, where all studies investigating the $\mathrm{PK} / \mathrm{PD}$ of the potential alternatives to carbapenems in ICU patients were included. (2) For clinical studies, we restricted inclusion to studies reporting mortality of patients receiving empirical or definitive treatment with a non-carbapenem therapy for an ESBL bacteremia in adult patients. Patients with community-, hospital- and healthcare-associated bacteremia were eligible for inclusion. (3) Finally, considering ecological studies, we included any published article reporting carbapenem-resistant Enterobacteriaceae (CRE). Among the eligible articles, studies were included if they reported on exposure to any previous antibiotic class as a risk factor associated with CRE acquisition.

\section{Results \\ Microbiological susceptibility}

Several studies suggested that ESBL-PE were susceptible to non-carbapenem beta-lactams. However, the prevalence of susceptibility depends on the species concerned, the antibiotic class and local epidemiology. ESBL-producing $E$. coli is usually regarded as more susceptible to all beta-lactams than ESBL-producing $K$. pneumoniae, piperacillin-tazobactam (Pip-Taz) being the most effective antibiotic [28]. North American data from the 2010-2014 SMART programs find that 4, 10 and 46\% of ESBL-producing $E$. coli were susceptible to ceftriaxone, cefepime and ceftazidime, respectively [28], whereas 96-98 and 69\% of ESBL-producing E. coli isolates from urinary tract [29] and from patients with pneumonia [30] were found susceptible in vitro to Pip-Taz, respectively. Conversely, only $26.9 \%$ of ESBL-producing Klebsiella spp. isolates from patients with pneumonia were susceptible to Pip-Taz [30]. Asian data on ESBL-producing $E$. coli find similar susceptibilities, with 1.6, 9.5, 33.4 and $84.5 \%$ isolates susceptible to cefotaxime, cefepime, ceftazidime and Pip-Taz, respectively [29]. It is noteworthy that in silico PK/PD studies aiming to evaluate the use of alternatives to carbapenems for treatment of ESBL-PE infections suggest that ESBL-Kp susceptibility is overestimated by conventional methods in comparison with E-test susceptibility testing.

\section{Pharmacokinetics and pharmacodynamics studies}

According to epidemiological data, two main antibiotics could be used as an alternative to carbapenems: piperacillin and cefoxitin. Others antibiotics suggested in the 
literature as temocillin, ceftolozane/tazobactam and/or ceftazidime/avibactam are less tested. Our goal was to define the optimal condition for using these antibiotics for ESBL-PE-related infections in ICU.

The pharmacokinetics of piperacillin in ICU patients was quite extensively investigated. There is, however, a lack of consensus on the pharmacokinetic/pharmacodynamic target to be achieved. Indeed targets as different as obtaining a free concentration $>$ MIC $(\mathrm{fT}>\mathrm{MIC})$ or $>4$ times the MIC ( $\mathrm{fT}>4 \mathrm{xMIC}$ ) for 50 or $100 \%$ of a dose interval have been considered [31-36]. This is a crucial point as the dose to be administered will vary considerably according to the chosen target. There are, however, increasing data supporting a minimal efficacy criteria of $\mathrm{fT}>\mathrm{MIC}=100 \%$ in ICU patients, while a total trough concentration/MIC ratio of at least three was found to prevent the emergence of resistance in vitro [37-40]. Therefore, based on these more drastic PK/PD endpoints, it seems a dose of $4.5 \mathrm{~g}$ TID given as intermittent infusions should not be considered any more in ICU patients with normal renal functions $[32,36]$. A 4.5-g $\times 4$ daily dose appears more convenient, provided it is administered as prolonged infusion of at least $3 \mathrm{~h}$ $[32,34]$. Indeed, for an intermittent bolus administration, a $4 \mathrm{gx} 4$ dose is associated with a very low probability of target attainment, even for the lowest PK/PD target of $\mathrm{T}>\mathrm{MIC}=50 \%$ [32]. However, even with a 4.5-g x 4 dose given by extended 3-h infusions, around one-third of the patients may not achieve a $\mathrm{fT}>\mathrm{MIC}=100 \%$, which supports the need for an individual dose adjustment using therapeutic drug monitoring [35]. Such a result strongly supports the use of continuous infusion, and since this administration mode provides a better outcome than intermittent infusion [24], we believe a 16-g daily dose given as a continuous infusion, following a 4.5-g loading dose, should be considered as a starting point in ICU patients with normal renal function. Such an approach was found relevant for the treatment of ventilator-associated pneumonia, as it allowed the achievement of alveolar concentrations $>16 \mathrm{mg} / \mathrm{L}$ (i.e., the clinical breakpoint for gram-negative bacteria).

Slightly different results were observed in morbidly obese ICU patients, for whom the elimination half-life of piperacillin seems to be increased, compared to nonobese patients, resulting in an increased fT > MIC for equivalent doses [33]. Consequently, a $4.5-\mathrm{g} \times 4$ daily dose given as a 4-h extended infusion should provide satisfying trough concentrations [33].

The pharmacokinetics of piperacillin in ICU patients undergoing continuous renal replacement therapy (CRRT) was also investigated, and similar results were found in case of venovenous hemofiltration or hemodiafiltration. A 4.5-g TID dose given as 30-min infusion should provide a free concentration > MIC for the entire dosing interval in almost all patients. Extending the infusion duration to $4 \mathrm{~h}$ should allow the attainment of several times the MIC. However, dose requirements seem to importantly depend on the membrane used and the effluent rate that are major aspects of CRRT poorly investigated to date $[41,42]$. An interesting point is that piperacillin concentration in the dialysate effluent is equal to the free plasma concentration and can therefore be used for the individual adaptation of the dose via therapeutic drug monitoring (TDM) [43]. To our knowledge, the PK of piperacillin in the context of intermittent hemodialysis was not investigated to date in ICU patients. Based on the results obtained in sepsis-free volunteers with chronic renal failure [44], a dose of $4.5 \mathrm{~g}$ bid could be used as a starting point, with a subsequent TDM-guided individual adjustment of the dose. Conflicting results are available about the percentage of the dose that is eliminated by a 4-h session of hemodialysis (i.e., from 10 to $50 \%)[45,46]$. However, because a supplemental elimination is likely to occur during hemodialysis, it seems preferable to administrate the drug just after the end of the hemodialysis session.

Cefoxitin PK in ICU patients was not investigated to date. By using the PK parameters obtained in healthy subjects, it was shown that for a 8-g daily dose of cefoxitin, only an administration by continuous infusion provided a high probability to achieve targets of $\mathrm{fT}>\mathrm{MIC}=100 \%$ and $\mathrm{fT}>4 \times \mathrm{MIC}=100 \%$ for ESBL-PE [47]. However, since PK differences are expected in ICU subjects, PK data in this population are obviously needed [48].

Concerning temocillin, a 2-g TID dose given as intermittent 30 -min infusion, provides a high probability to attain $\mathrm{fT}>\mathrm{MIC}=100 \%$ in ICU patients with normal renal function, provided the MIC is $\leq 4 \mathrm{mg} / \mathrm{L}$. For higher MIC, administration of the same daily dose by continuous infusion is preferable [49]. In summary, among the different antibiotics suggested as alternatives to carbapenems, Pip-Tz is the one with the most frequent published PK/PD data in ICU. High daily doses and prolonged infusion should be promoted for ESBL-PE-related infections in ICU patients.

\section{Clinical studies}

The article selection process is shown in Fig. 1. Of the 54 articles selected initially, 23 provided data among patients treated with BL/BLIs for ESBL-producing Enterobacteriaceae-related infections (Table 1). Most of the published studies were retrospective (17/23; 73.9\%), and all others were observational. Community-acquired, healthcare-associated and nosocomial infections were included without distinction. Among these 23 studies, 9 (39.1\%), $6(26 \%)$ and $7(30.4 \%)$ evaluated antibiotic therapy as 


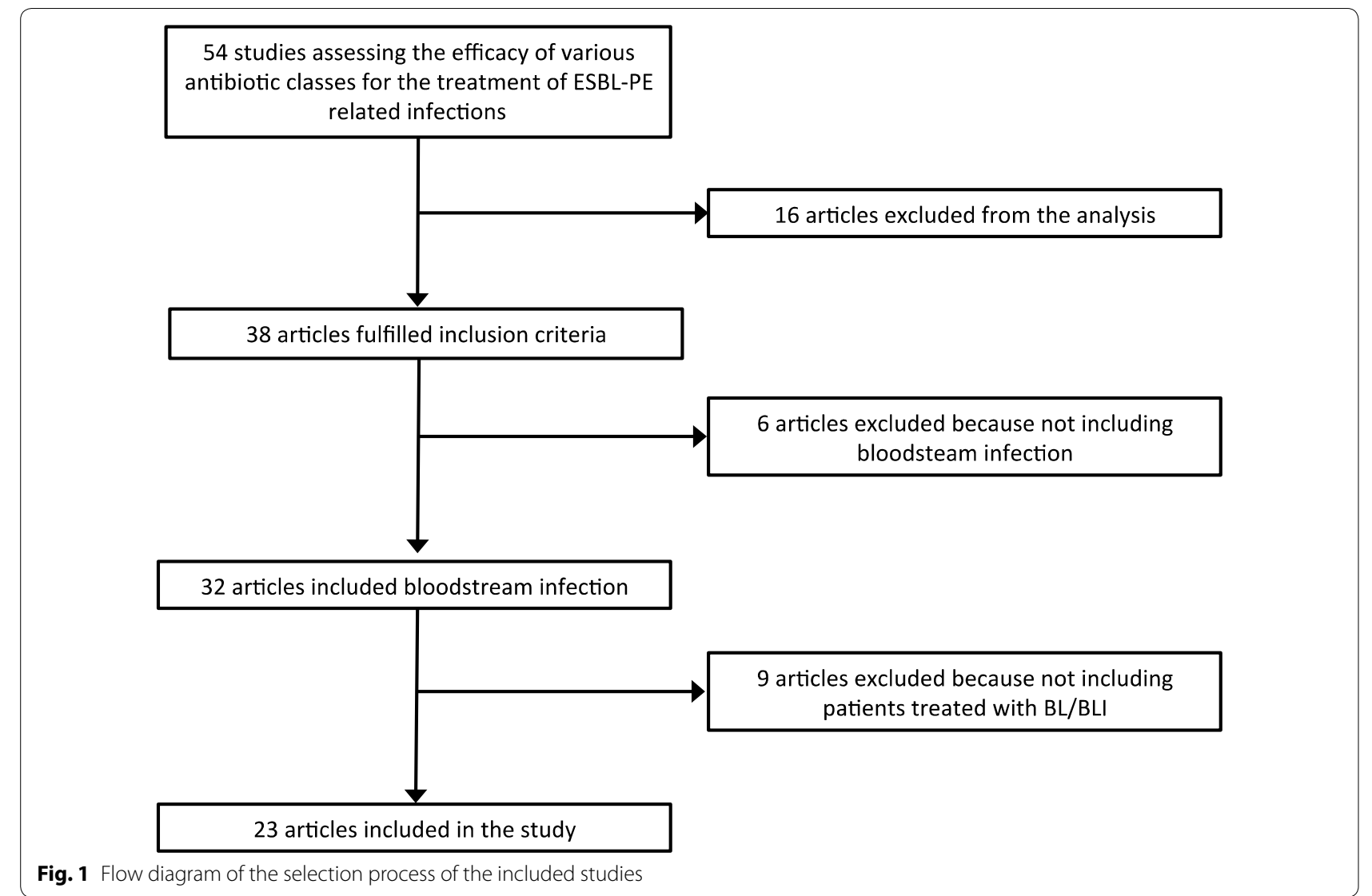

empirical therapy (ETC), definitive therapy or both, respectively. Among carbapenems, the selected molecule was available in $53 \%$ of included studies and imipenemcilastatin was the most frequently used (45.7\% of studies) followed by meropenem (35.2\%) and ertapenem (19.1\%).

Only $3(13 \%)$ studies reported the doses of antibiotics $[19,20,50]$ and none reported the modalities of antibiotic's administration. Indeed administered doses in patients without renal failure were variable; however, imipenem was used in most cases at an average dose of $0.5 \mathrm{~g}$ every $6 \mathrm{~h}$, whereas $1 \mathrm{~g}$ every $8 \mathrm{~h}$ and $1 \mathrm{~g}$ every $24 \mathrm{~h}$ were used for meropenem and ertapenem, respectively. The two species most frequently involved were $E$. coli and K. pneumoniae. All patients included in these studies had bacteremia, and the two most frequent sites of infection were urinary tract and intra-abdominal infection. MIC was taken into account in adjusting antibiotic therapy in 11 (47.8\%) of the 23 studies.

As mentioned above, 11 studies included between 6 and $131 \mathrm{ICU}$ patients. In fact, some of the same patients were included in different cohorts [12, 51]. Only 4 studies [52-55] included patients with pneumonia caused by ESBL-PE, representing 8-50\% of patients with ESBL-PErelated infections, indicating that less than 30 patients with ESBL-related pneumonia could be evaluated. Data regarding outcome for patients treated with carbapenems versus alternatives were available from 20 (86.9\%) of the 23 studies including bacteremic patients. Surprisingly, potential confounding factors, such as severity of underlying diseases or of infection, were seldom reported.

Among studies including ICU patients, 6 (56\%) compared BL/BLIs to carbapenems as empirical therapy. However, BL/BLIs was the only alternative compared to carbapenems in only 3 studies [12, 20,51]. In these studies, E. coli and K. pneumoniae represented more than two-third of the isolates and MICs were taken into account in only one study [20]. The difference of mortality didn't reach statistical significance in two studies [12, 51]. However, Ofer-friedman et al. [20] conducted a multicenter observational study including non-urinary BSI and comparing $\mathrm{BL} / \mathrm{BLI}$ to carbapenem for the treatment of ESBL. In contrast to other studies, E. coli accounted for only half of the bloodstream infections; the median piperacillin MIC was $8 \mathrm{mg} / \mathrm{L}$, and approximately half of patients required ICU care. In this study, the mortality was significantly higher in the piperacillin-tazobactam group [OR 7.9 (1.2-53)]. Thus, BL/BLIs may lead a poorer outcome than carbapenem therapy for critically 


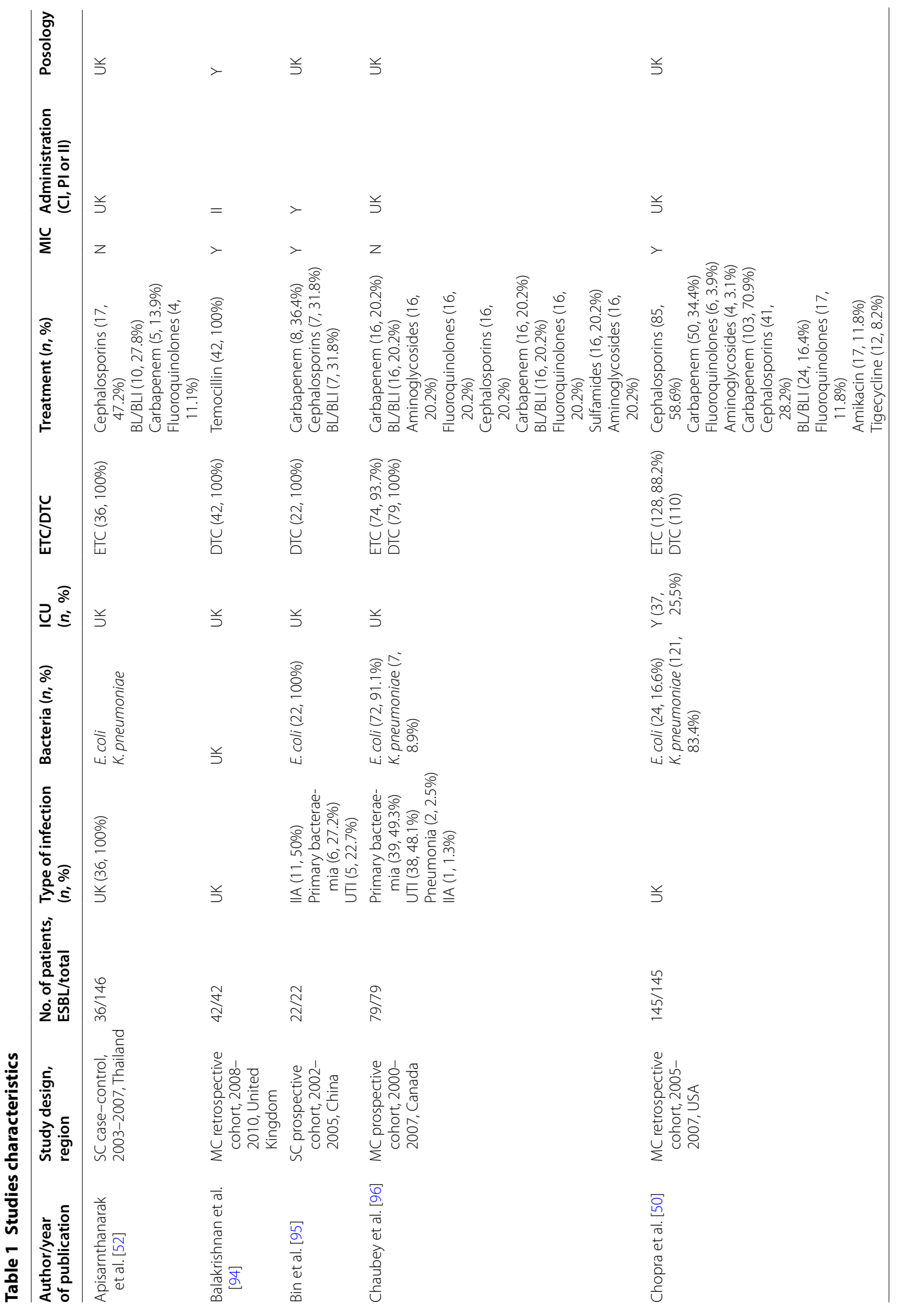




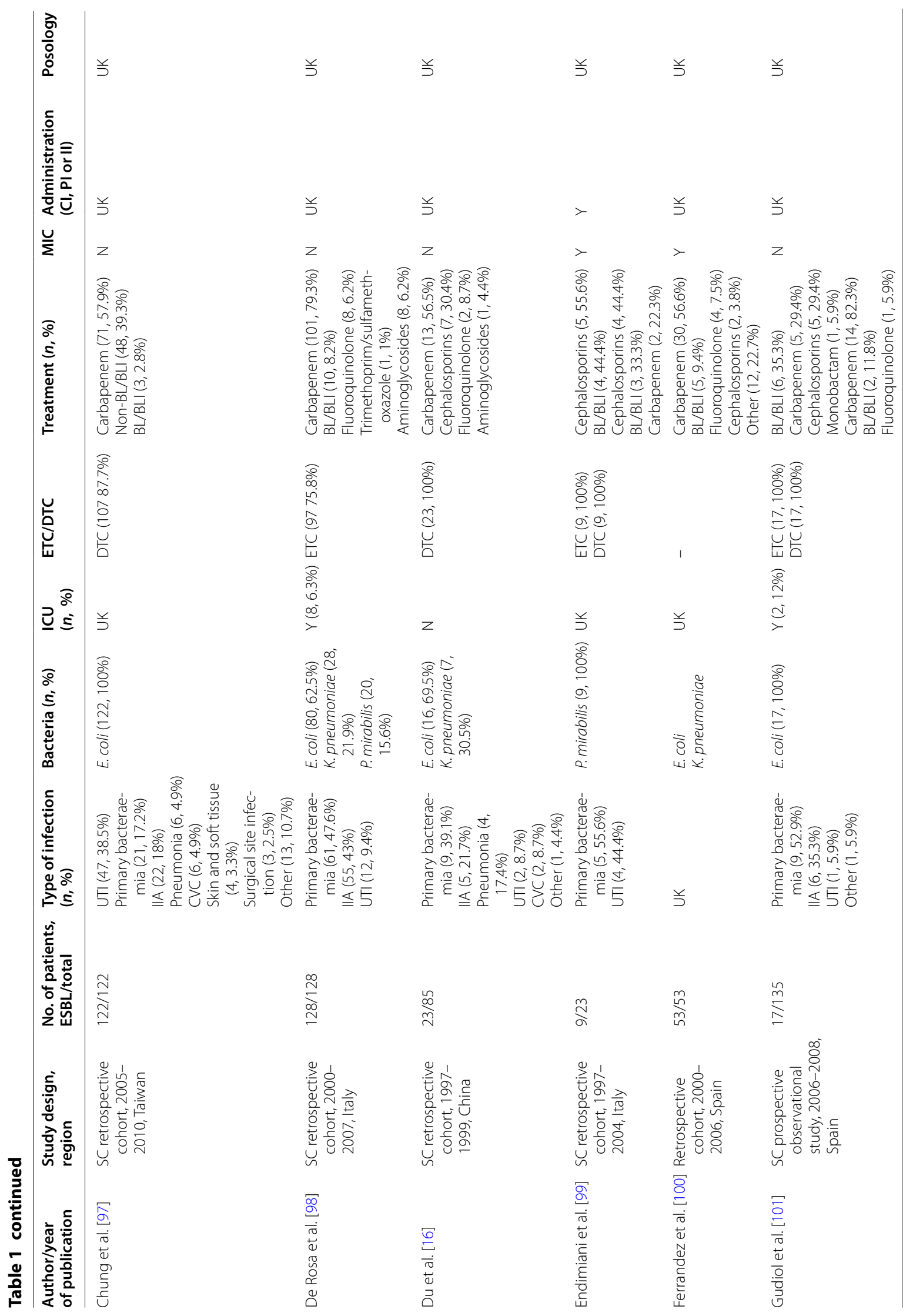




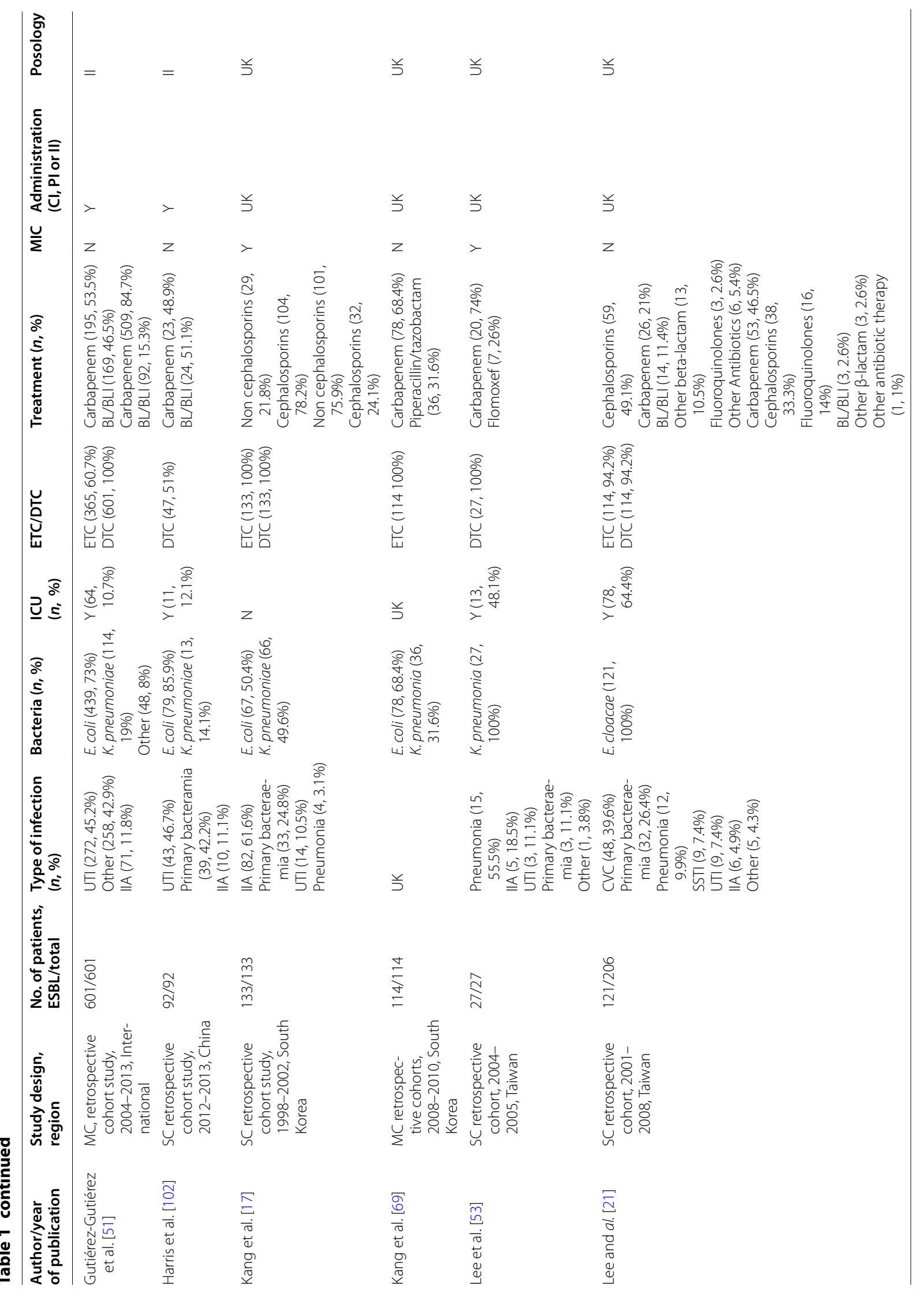




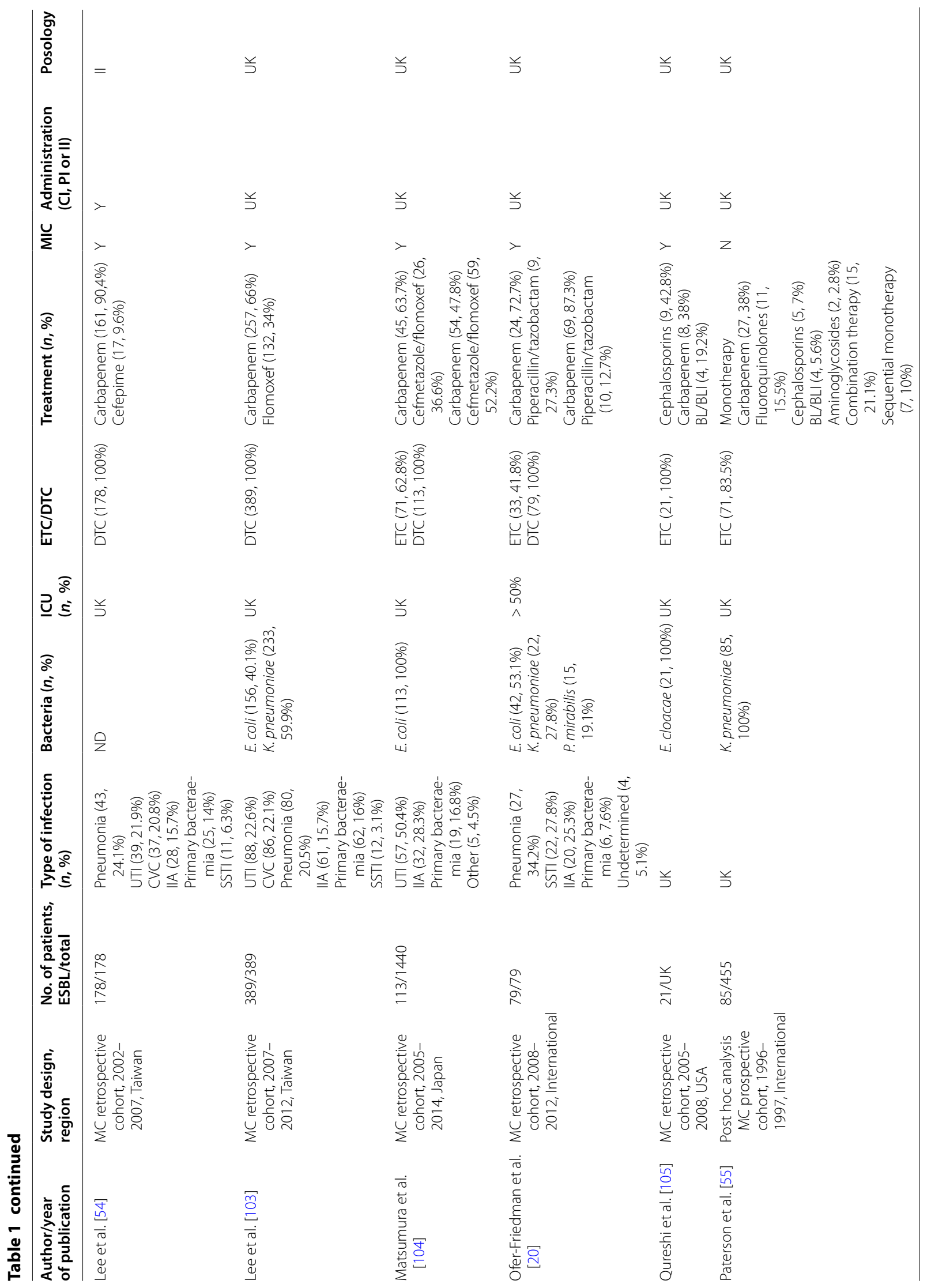




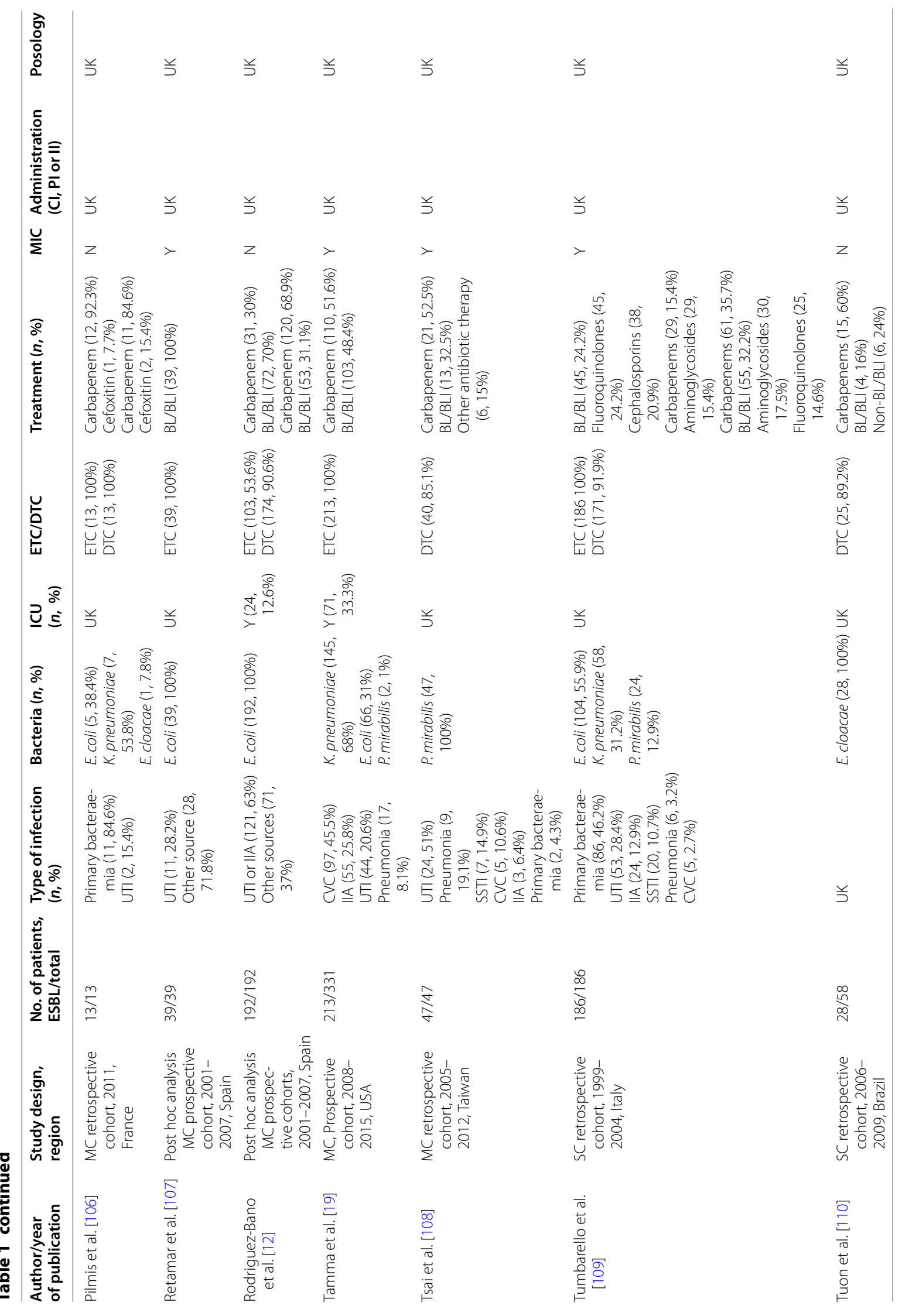




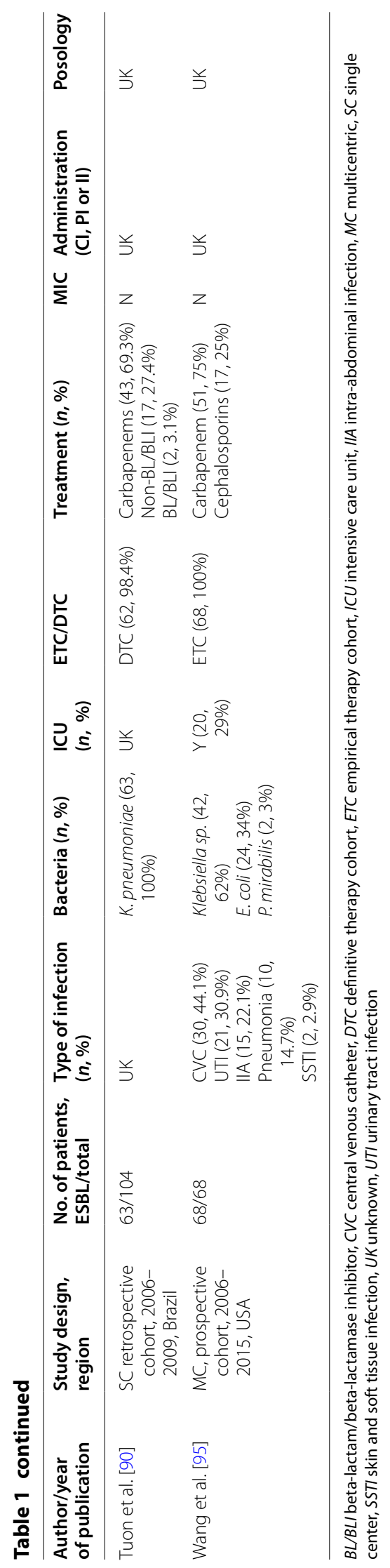


ill patients with ESBL-PE infection from non-urinary sources.

Finally $7 / 11$ (63\%) studies compared BL/BLIs to carbapenems as definitive therapy, of which $4(36.3 \%)$ compared BL/BLIs as the only alternative to carbapenems $[12,19,20,22,51]$. It should be noted that only one of these studies took into account MICs [20], whereas none took into account dosages and modalities of administration for assessing the effectiveness of therapy [19].

\section{Ecological studies}

While initial research suggested the relative safety of imipenem-cilastatin on the intestinal microbiota [56], the recent analysis of rectal colonization of large number of ICU patients found that even a brief exposure to imipenem is a risk factor for carriage of resistant GNB in the intestinal flora [6].

The effect of non-carbapenem antibiotics on the emergence of multidrug-resistant bacteria and specifically carbapenem resistance is a major issue. In animal models, imipenem-cilastatin had no effect on the indigenous microflora [56]. In a mouse model, clindamycin and piperacillin-tazobactam promoted colonization, while ertapenem did not promote the establishment of intestinal colonization with KPC-Kp [57]. Also several authors highlighted the risk associated with the emergence/ selection of resistant strains when using Pip-Taz. Firstly, in vitro/in vivo studies [27] suggested that Pip-Taz seems to be less resistant to the inoculum effect comparing to carbapenems. Secondly, several clinical studies [58] underlined the risk of promoting vancomycin-resistant enterococci (VRE) colonization. Finally the emergence of carbapenem-resistant PE has been documented for a variety of antibiotics in the clinical setting [59] (Table 2): Fluoroquinolones [60, 61], extended-spectrum cephalosporin [62], antipseudomonal penicillins [63] and $\beta$-lactams/ $\beta$-lactamase inhibitors [64] have all been identified as risk factors for carbapenem resistance in Klebsiella pneumoniae.

Whether carbapenem is the only antibiotic class associated with the selection of carbapenem-resistant gram-negative isolates is an important issue, especially regarding the worldwide spread of carbapenemase-producing Enterobacteriaceae (CPE). These data suggest that antibiotics that disturb the intestinal anaerobic microflora and lack significant activity against KPC-Kp may promote colonization by this organism [65] (Table 3).

\section{Discussion and conclusion}

In our review of BL/BLI for the treatment of ESBL-PE, we found that they may be an alternative to carbapenems in a selected number of cases, based on antibiogram and CMI data, and always with $\mathrm{pk} / \mathrm{pd}$ optimization.
The use of alternatives for empirical therapy in suspected ESBL-related infections is usually limited by the level of resistance [66], the risk of selecting resistant mutants [6] and clinical effectiveness [19]. We focused on BL/BLIs, chiefly piperacillin-tazobactam. Indeed, based on epidemiological data, the use of third- or fourthgeneration cephalosporins such as cefepime is limited because of a high proportion of resistant isolates [66] that varies between 10 and $50 \%$ and concerns on their clinical efficacy with the associated risks of adverse patient outcomes [54]. The use of other alternatives such as temocillin is limited by unfavorable PK/PD parameters in critically ill patients [49].

The efficacy of Pip/Taz antibiotics on ESBL-PE depends on the variety and amount of enzyme produced by the isolates (Table 4). Overall, the rate of susceptibility of ESBL-PE to Pip/Taz is around $80 \%$ [28]. It may be reduced when the organisms produce multiple ESBLs, particularly if they also harbor an AmpC beta-lactamase [67]. Also it will vary within and between beta-lactamases classes [68]. The presence of additional resistance mechanisms may further decrease the activity of Pip/Taz against ESBL-producing organisms.

In the absence of a well-designed prospective randomized study comparing carbapenems to non-carbapenems in ICU patients infected with ESBL-PE, we must rely on the evidence provided by observational data. Observational studies considering the empirical treatment of ESBL-related infections with BL/BLIs have infrequently included ICU patients [12] and more often involved urinary or biliary tract infection caused by $E$. coli species [51]. Although several studies suggested no difference in mortality $[12,51,69], 2$ publications raise the warning of a potential negative impact of BL/BLI when used in patients with ESBL-PE $[19,20]$.

Furthermore, when analyzing those publications with a focus on the use of alternatives to carbapenems for definitive therapy, a number of limitations hamper the interpretation of studies comparing BL/BLI to carbapenems.

Firstly most of these studies were not designed to compare different antibiotic strategies. Secondly, the authors did not take into account the severity of underlying diseases, delays to antimicrobial treatment and effectiveness source control, which are all major predictors of outcome [70]. Thirdly, patients included differed largely across studies, with regard to sources of bacteremia, species involved and type of beta-lactamases; moreover, various antibiotics and different daily doses administered were included in the "alternative" group.

Fourthly, most of the studies included infections related to ESBL-producing Escherichia coli and did not account for the impact of MICs and pharmacodynamics data. The impact of MIC seems to be crucial for therapeutic 
Table 2 Studies addressing the risk related to previous antibiotic therapy and emergence of carbapenem-resistant Enterobacteriaceae

\begin{tabular}{|c|c|c|c|c|c|}
\hline & Year & Study design & Type of infection & Antibiotic concerned & OR, $95 \% \mathrm{Cl}$ \\
\hline Wang [62] & 2016 & $\begin{array}{l}\text { Retrospective case-case-con- } \\
\text { trol }\end{array}$ & Nosocomial infection & $\begin{array}{l}\text { Third-fourth-generation } \\
\text { cephalosporins } \\
\text { Carbapenems }\end{array}$ & $\begin{aligned} 4.557(1.971-10.539) \\
4.058(1.753-9.397)\end{aligned}$ \\
\hline Mittal G [80] & 2016 & Prospective & Colonization & Aminoglycosides & $4.14(1.14-14.99)$ \\
\hline Ling [81] & 2015 & Retrospective case-control & Infection or colonization & $\begin{array}{l}\text { Penicillins } \\
\text { Glycopeptides }\end{array}$ & $\begin{array}{l}4.640(1.529-14.079) \\
5.162(1.377-19.346)\end{array}$ \\
\hline Jiao Y [82] & 2015 & Retrospective case-control & Infection or colonization & $\begin{array}{l}\text { Glycopeptides } \\
\text { Cefoperazone plus sulbactam }\end{array}$ & $\begin{array}{l}43.84(1.73-1111.9) \\
49.56,(1.42-1726.72)\end{array}$ \\
\hline Candevir [83] & 2015 & Retrospective cohort & Infection & $\begin{array}{l}\text { Meropenem } \\
\text { Third-generation cephalo- } \\
\text { sporins }\end{array}$ & $\begin{array}{l}3.244(1.193-8.819) \\
\quad 3.590(1.056-12.209)\end{array}$ \\
\hline Gómez Rueda [84] & 2014 & $\begin{array}{l}\text { Retrospective case-case-con- } \\
\text { trol }\end{array}$ & Infection & Carbapenems & $3.3(1.2-9.3)$ \\
\hline Ahn [85] & 2014 & Retrospective case-control & Colonization/infection & $\begin{array}{l}\text { Fluoroquinolones } \\
\text { Carbapenems }\end{array}$ & $\begin{array}{l}2.82(1.14-6.99) \\
4.56(1.44-14.46)\end{array}$ \\
\hline Mantzarlis [86] & 2013 & Prospective cohort & Pneumonia & Colistin* & 1.156 per day (1.010-1.312) \\
\hline Dizbay [87] & 2013 & Prospective cohort & Nosocomial infection & Imipenem & $3.35(1.675-6.726)$ \\
\hline Orsi [88] & 2013 & Retrospective case control & BSI & Carbapenem & $7.74(1.70-35.2)$ \\
\hline Chang [89] & 2011 & Retrospective case-control & $\mathrm{BSI}$ & Carbapenem & $29.17(1.76-484.70)$ \\
\hline Falagas [63] & 2007 & Retrospective case control & KPC infection & $\begin{array}{l}\text { Fluoroquinolones } \\
\text { Antipseudomonal antibiotics }\end{array}$ & $\begin{aligned} 4.54(1.18-11.54) \\
2.6(1.00-6.71)\end{aligned}$ \\
\hline Schwaber [61] & 2008 & $\begin{array}{l}\text { Retrospective case-case-con- } \\
\text { trol }\end{array}$ & CRKp colonization & $\begin{array}{l}\text { Antibiotics } \\
\text { Fluoroquinolones }\end{array}$ & $\begin{array}{r}4.4(1-19.2) \\
7.2(1.1-49.4)\end{array}$ \\
\hline Gasink [60] & 2009 & Retrospective case-control & KPC infection/colonization & $\begin{array}{l}\text { Fluoroquinolones } \\
\text { Third-generation cephalo- } \\
\text { sporin }\end{array}$ & $\begin{array}{l}3.39(1.5-7.66) \\
2.55(1.18-5.22)\end{array}$ \\
\hline Papadimitriou [64] & 2012 & Prospective cohort & CRKp colonization & $\begin{array}{l}\mathrm{BL} / \mathrm{BLI} \\
\text { Carbapenems }\end{array}$ & $\begin{array}{l}6.7(1-26.2) \\
5.2(1-32.9)\end{array}$ \\
\hline Tuon [90] & 2012 & Retrospective case-control & KPC bacteremia & Fluoroquinolones & $28.9(1.85-454.6)$ \\
\hline Papadimitriou [91] & 2014 & Prospective cohort & KPC bacteremia & Aminoglycosides & $2.3(1.1-4.7)$ \\
\hline Gagliotti [79] & 2014 & Case-control & KPC colonization & $\begin{array}{l}\text { Carbapenems } \\
\text { Any antibiotic (other than } \\
\text { carbapenems) }\end{array}$ & $\begin{array}{l}3.67(1.37-9.83) \\
2.83(1.10-7.31)\end{array}$ \\
\hline Maseda [92] & 2016 & Retrospective & CPE isolate colonization & $\begin{array}{l}\text { Third-fourth-generation } \\
\text { cephalosporins } \\
\text { BL/BLI }\end{array}$ & $\begin{array}{r}27.96(6.88-113.58) \\
11.71(4.51-30.43)\end{array}$ \\
\hline
\end{tabular}

KPC Klebsiella pneumoniae-producing carbapenemase, CRKp carbapenem-resistant Klebsiella pneumoniae, BL/BL/ beta-lactams associated with beta-lactamase inhibitors, BSI bloodstream infection

efficacy when using alternatives to carbapenems as the cornerstone of treatment. Several studies [12] emphasize the risk of treatment failure when using a BL/BLI or third-generation cephalosporin for therapy of infection with isolates having MICs higher than the breakpoints. Indeed, as suggested by a recent pharmacological study, the efficacy of BL/BLI in the treatment of ESBL-related infections is related to the concentration reached in the plasma and at the site of infection [71]. However, as demonstrated by several authors [72] the probability of attaining therapeutic drug levels in ICU patients is low and variable depending on the antibiotic considered and dosing strategies [35]. Also it seems important to have MIC for piperacillin-tazobactam before using this class of antibiotic. Considering several problems related to piperacillin-tazobactam gradient tests and differences noted between gradient tests and broth microdilution, it is recommended now to use broth microdilution.

There are now enough published data on the $\mathrm{pk} / \mathrm{pd}$ of piperacillin/tazobactam to recommend the use of high daily doses and prolonged infusion ICU patients and in all cases of difficult to treat pathogens such as ESBL-PE.

The ecological consequences of a given antibiotic class depend on the amount of drug reaching the different microbiota. The net result depends on both the antibiotic concentrations achieved and the susceptibility of bacterial species in the microbiota. All antibiotics alter the composition, diversity and density of the microbiota 
Table 3 (Adapted from [14, 15]) usual breakpoints and susceptibility of ESBL-producing Enterobacteriaceae

\begin{tabular}{|c|c|c|c|c|}
\hline & Susceptibility (\%) & Breakpoints (mg/L) & Ecological impact & Comments \\
\hline Third-generation cephalosporins & $\begin{array}{l}\text { Escherichia coli: < 10\% } \\
\text { Klebsiella species: } 3 \%\end{array}$ & $\begin{array}{l}\text { EUCAST: } S \leq 1 \\
\text { CLSI: } S \leq 1\end{array}$ & +++ & $\begin{array}{l}\text { Only for targeted therapy or de- } \\
\text { escalation } \\
\text { MIC required }\end{array}$ \\
\hline Cefepime & $\begin{array}{l}\text { E. coli: } 5-30 \% \\
\text { K. pneumoniae: } 5-60 \%\end{array}$ & $\begin{array}{l}\text { EUCAST: } S<1 \\
\text { CLSI: } S \leq 2\end{array}$ & +++ & $\begin{array}{l}\text { Frequent failure if MICs }>1 \mathrm{mg} / \mathrm{L} \\
\text { MIC required }\end{array}$ \\
\hline Cefoxitin & E. coli: $80 \%$ & EUCAST: NA & ++ & PK optimization \\
\hline Ceftolozane-tazobactam & $\begin{array}{l}\text { E. coli: } 85-95 \% \\
\text { K. pneumoniae: } 40-65 \%\end{array}$ & $\begin{array}{l}\text { EUCAST: } S \leq 1 \\
\text { CLSI: } S \leq 8\end{array}$ & $?$ & \\
\hline Ceftazidime-avibactam & $\begin{array}{l}\text { E. coli: } 98-100 \% \\
\text { K. pneumoniae: } 90-100 \%\end{array}$ & $\begin{array}{l}\text { EUCAST: } S \leq 8 \\
\text { CLSI: } S \leq 8\end{array}$ & $?$ & Probably as effective as carbapenems \\
\hline Temocillin & $\begin{array}{l}\text { E. coli } 61 \%(\mathrm{CMI} \leq 8) \\
\text { E. coli } 99 \%(\mathrm{CMI} \leq 32)\end{array}$ & $\begin{array}{l}\text { EUCAST: } S \leq 8 \\
\text { EUCAST: } S \leq 32 \text { (urinary) } \\
\text { CLSI: } S \leq 8 \\
\text { CLSI: } S \leq 32 \text { (urinary) }\end{array}$ & \pm & $\begin{array}{l}\text { PK optimization (high dosage and } \\
\text { prolonged infusion) }\end{array}$ \\
\hline
\end{tabular}

CLSI Clinical and Laboratory Standard Institute, EUCAST European Committee on Antimicrobial Susceptibility Testing, MIC minimum inhibitory concentration, NA not applicable, PK pharmacokinetic, VAP ventilator-associated pneumonia

Table 4 (Adapted from Bonomo and Van Duin) Activity in clinical practice of different beta-lactamase inhibitors, according to type of enzymes $[68,111]$

\begin{tabular}{|c|c|c|c|c|c|c|}
\hline Enzymes & Class & Substrates & Clavulanic acid & Sulbactam & Tazobactam & Avibactam \\
\hline TEM-1, TEM-2, SHV-1 & A & Penicillins, early cephalosporins & + & - & + & + \\
\hline TEM-3, SHV-2 CTX-M-14 & A & Extended-spectrum cephalosporins, monobactams & - & - & + & + \\
\hline $\mathrm{KPC}-2, \mathrm{KPC}-3$ & A & Broad spectrum including carbapenems & - & - & - & + \\
\hline IMP-1, NDM-1, VIM-1 & B & $\begin{array}{l}\text { Broad spectrum including carbapenems, but not } \\
\text { monobactams }\end{array}$ & - & - & - & - \\
\hline Escherichia coli AmpC & C & Cephalosporins & - & - & \pm & + \\
\hline OXA-48 & $\mathrm{D}$ & Carbapenem & - & - & - & + \\
\hline
\end{tabular}

and select for antibiotic resistance [73]. The "ecological consequences," however, may differ according to the antibiotic used. Increasing consumption of carbapenems raises concerns on the spread of carbapenem-resistant Enterobacteriaceae and specifically carbapenemase-producing Enterobacteriaceae (CPE) [74]. Also, there are some discrepancies between the first published studies $[75,76]$ and the more recent ones [6] regarding the ecological effect of carbapenems. There is a significant correlation between carbapenem consumption and rates of Pseudomonas aeruginosa resistance to imipenem and meropenem $[6,53]$. However, this mechanism of resistance is not due to the effect of antibiotics on the microbiota, but the consequence of chromosomal mutation. Earlier human studies [77] and animal models [78] suggested a limited impact on the microbiota of this class of antibiotics. However, whatever the antibiotic used, selective antibiotic pressure is an important determinant of emergence and dissemination of antibiotic resistance [61, 62], and the increasing use of carbapenems will necessarily be associated with the increase in multidrug-resistant organisms [65]. Our review underlines the fact that the administration of several other antibiotics can also be associated with the emergence of carbapenem-resistant organisms [60-64, 79-92]. Nevertheless, the heterogeneity of studies makes their comparison difficult. Indeed, all these studies are subject to several limitations, including inadequate adjustment for important confounding variables, control group selection, extent of prior antibiotic exposure and measurements of resistance outcomes.

One of the limitations of our study lies in the fact that we did not mentioned the two recent BL/BLIs approved by FDA and EMA, ceftolozane-tazobactam and ceftazidime-avibactam which are active in vitro against ESBLproducing Enterobacteriaceae. Several recent studies highlighted the in vitro efficacy of these two antibiotics on ESBL-producing Enterobacteriaceae [67, 93]. Also clinical data are scarce. Indeed for nosocomial pneumonia, a phase III study (MK-7625A-008) is currently leaded using ceftolozane-tazobactam.

A definitive answer to the question addressed in this review would need a randomized study conducted in ICU, including severe infections related to ESBL-PE. Cases should be selected according to the results of 
antibiotic susceptibility tests, and the trial should compare carbapenems to BL/BLI as definitive therapy. Pending such a trial, piperacillin-tazobactam should be used with caution for treatment of ESBL-PE-related infections. In ICU patients, empirical use should be avoided, and definitive therapy should be reserved to patients in clinical stable condition, after microbial documentation and results of susceptibility tests, together with adapting the administered dose and modalities of infusion to the MIC of the infecting microorganism in order to reach pharmacological targets.

\section{Abbreviations}

ADE: antimicrobial de-escalation; BL/BLI: beta-lactam/beta-lactamase inhibitor; CLSI: Clinical and Laboratory Standards Institute; CRB: carbapenem-resistant bacteria; CRE: carbapenem-resistant Enterobacteriaceae; EMA: European Medicine Agency; ESAC: European Surveillance of Antimicrobial Consumption; EUCAST: European Committee on Antimicrobial Susceptibility Testing; FDA: Food and Drug Administration; ICU: intensive care unit; KPC: Klebsiella-producing carbapenemase; MIC: minimal inhibitory concentration; OR: odds ratio; PD: pharmacodynamic; PK: pharmacokinetic; TDM: therapeutic drug monitoring; TID: three times in a day.
\end{abstract}

\begin{abstract}
Authors' contributions
BP contributed to conception and design of the study, responsible for the "clinical studies" portion and gave final approval of the version to be published. VJ contributed to conception and design of the study, responsible for the "pharmacokinetics and pharmacodynamic studies" portion and gave final approval of the version to be published. AT revised the manuscript critically for important intellectual content and gave final approval of the version to be published. JRZ contributed to conception and design of the study, responsible for the "ecological studies" portion and gave final approval of the version to be published. CBB involved in design of the study, revised it critically for important intellectual content and gave final approval of the version to be published.
\end{abstract}

\begin{abstract}
Author details
${ }^{1}$ Service de maladies infectieuses et tropicales, Hôpital Necker Enfants malades, Service de maladies infectieuses et tropicales, Université Paris Descartes, Paris, France. ${ }^{2}$ Equipe mobile de microbiologie clinique, Groupe Hospitalier Paris Saint-Joseph, Paris, France. ${ }^{3}$ Service de Pharmacologie, Hôpital Européen Georges Pompidou, Université Paris Descartes, Paris, France. ${ }^{4}$ INSERM U1 129, Paris, France. ${ }^{5}$ Intensive Care Unit, The Redcliffe Hospital, Brisbane, Australia. ${ }^{6}$ Burns, Trauma and Critical Care Research Centre, The University of Queensland, Brisbane, Australia. ${ }^{7}$ Département de Microbiologie Clinique, Unité de Contrôle et de Prévention du risque Infectieux, Groupe Hospitalier Paris Seine Saint-Denis, AP-HP, CHU Avicenne, 125 rue de Stalingrad, 9300 Bobigny, France. ${ }^{8}$ Infection Control Unit, IAME, UMR 1137, Université Paris 13, Sorbonne Paris Cité, Paris, France. ${ }^{9}$ Réanimation médicale, Hôpital Henri Mondor, Univer-
\end{abstract} sité Paris Est Créteil (UPEC), Créteil, France.

\section{Acknowledgements}

Not applicable.

\section{Competing interests}

$\mathrm{BP}, \mathrm{AT}$ and $\mathrm{CBB}$ declare that they have no competing interests. VJ has received research grants from Astellas, Sanofi-Aventis, Biocodex and travel Grants from MSD. JRZ has participated in an advisory board for MSD.

\section{Availability of data and materials}

Details regarding the literature search strategy and the terms used are provided in online supplement. We fully agree to discuss and share key data with interested individuals.

\section{Consent for publication}

Not applicable.
Ethics approval and consent to participate Not applicable.

\section{Publisher's Note}

Springer Nature remains neutral with regard to jurisdictional claims in published maps and institutional affiliations.

Received: 3 May 2017 Accepted: 26 October 2017

Published online: 10 November 2017

\section{References}

1. Arpin C, Quentin C, Grobost F, Cambau E, Robert J, Dubois V, et al. Nationwide survey of extended-spectrum \{beta\}-lactamase-producing enterobacteriaceae in the French community setting. J Antimicrob Chemother. 2009:63:1205-14.

2. Meier S, Weber R, Zbinden R, Ruef C, Hasse B. Extended-spectrum $\beta$-lactamase-producing Gram-negative pathogens in communityacquired urinary tract infections: an increasing challenge for antimicrobial therapy. Infection. 2011;39:333-40.

3. Prinapori R, Guinaud J, Khali A, Lecuyer H, Gendrel D, Lortholary O, et al. Risk associated with a systematic search of extended-spectrum B-lactamase-producing Enterobacteriaceae. Am J Infect Control. 2013:41:259-60.

4. Barbier F, Pommier C, Essaied W, Garrouste-Orgeas M, Schwebel C, Ruckly S, et al. Colonization and infection with extended-spectrum $\beta$-lactamase-producing enterobacteriaceae in ICU patients: what impact on outcomes and carbapenem exposure? J Antimicrob Chemother. 2016;71:1088-97.

5. http://ecdc.europa.eu/en/eaad/antibiotics-news/Documents/antimicrobial-consumption-ESAC-Net-summary-2015.pdf.

6. Armand-Lefèvre L, Angebault C, Barbier F, Hamelet E, Defrance G, Ruppé E, et al. Emergence of imipenem-resistant gram-negative bacilli in intestinal flora of intensive care patients. Antimicrob Agents Chemother. 2013:57:1488-95.

7. Tabah A, Cotta MO, Garnacho-Montero J, Schouten J, Roberts JA, Lipman J, et al. A systematic review of the definitions, determinants, and clinical outcomes of antimicrobial de-escalation in the intensive care unit. Clin Infect Dis Off Publ Infect Dis Soc Am. 2016;62:1009-17.

8. Kalil AC, Metersky ML, Klompas M, Muscedere J, Sweeney DA, Palmer $\mathrm{LB}$, et al. Management of adults with Hospital-acquired and ventilatorassociated pneumonia: 2016 clinical practice guidelines by the infectious diseases society of America and the American thoracic society. Clin Infect Dis. 2016;63:e61-111.

9. Rhodes A, Evans LE, Alhazzani W, Levy MM, Antonelli M, Ferrer R, et al. Surviving sepsis campaign: international guidelines for management of sepsis and septic shock: 2016. Intensive Care Med. 2017;43:304-77.

10. Paterson DL. Recommendation for treatment of severe infections caused by Enterobacteriaceae producing extended-spectrum betalactamases (ESBLs). Clin Microbiol Infect Off Publ Eur Soc Clin Microbiol Infect Dis. 2000;6:460-3.

11. Piroth L, Aubé H, Doise JM, Vincent-Martin M. Spread of extendedspectrum beta-lactamase-producing Klebsiella pneumoniae: are betalactamase inhibitors of therapeutic value? Clin. Infect. Dis. Off. Publ. Infect. Dis. Soc. Am. 1998;27:76-80.

12. Rodríguez-Baño J, Navarro MD, Retamar P, Picón E, Pascual Á. ExtendedSpectrum Beta-Lactamases-Red Española de Investigación en Patología Infecciosa/Grupo de Estudio de Infección Hospitalaria Group. $\beta$-Lactam/ $\beta$-lactam inhibitor combinations for the treatment of bacteremia due to extended-spectrum $\beta$-lactamase-producing Escherichia coli: a post hoc analysis of prospective cohorts. Clin Infect Dis Off Publ Infect Dis Soc Am. 2012;54:167-74.

13. Ng TM, Khong WX, Harris PNA, De PP, Chow A, Tambyah PA, et al. Empiric piperacillin-tazobactam versus carbapenems in the treatment of bacteraemia due to extended-spectrum beta-lactamase-producing enterobacteriaceae. PLOS ONE. 2016;11:e0153696.

14. EUCAST: Clinical breakpoints [cited 2015 Aug 18]. http://www.eucast. org/clinical_breakpoints/. 
15. CLSI Publishes New Antimicrobial Susceptibility Testing Standards_CLSI [cited 2016 Aug 5]. http://clsi.org/blog/2015/01/08/ clsi-publishes-new-antimicrobial-susceptibility-testing-standards/.

16. Du B, Long Y, Liu H, Chen D, Liu D, Xu Y, et al. Extended-spectrum beta-lactamase-producing Escherichia coli and Klebsiella pneumoniae bloodstream infection: risk factors and clinical outcome. Intensive Care Med. 2002;28:1718-23.

17. Kang C-I, Kim S-H, Park WB, Lee K-D, Kim H-B, Kim E-C, et al. Bloodstream infections due to extended-spectrum beta-lactamase-producing Escherichia coli and Klebsiella pneumoniae: risk factors for mortality and treatment outcome, with special emphasis on antimicrobial therapy. Antimicrob Agents Chemother. 2004;48:4574-81.

18. Wang R, Cosgrove SE, Tschudin-Sutter S, Han JH, Turnbull AE, Hsu AJ, et al. Cefepime therapy for cefepime-susceptible extended-spectrum $\beta$-lactamase-producing enterobacteriaceae bacteremia. Open Forum Infect Dis. 2016;3:ofw132.

19. Tamma PD, Han JH, Rock C, Harris AD, Lautenbach E, Hsu AJ, et al. Carbapenem therapy is associated with improved survival compared with piperacillin-tazobactam for patients with extended-spectrum $\beta$-lactamase bacteremia. Clin Infect Dis Off Publ Infect Dis Soc Am. 2015;60:1319-25.

20. Ofer-Friedman H, Shefler C, Sharma S, Tirosh A, Tal-Jasper R, Kandipalli $D$, et al. Carbapenems versus piperacillin-tazobactam for bloodstream infections of nonurinary source caused by extended-spectrum beta-lactamase-producing enterobacteriaceae. Infect Control Hosp Epidemiol. 2015;36:981-5.

21. Lee C-C, Lee N-Y, Yan J-J, Lee H-C, Chen P-L, Chang C-M, et al. Bacteremia due to extended-spectrum-beta-lactamase-producing Enterobacter cloacae: role of carbapenem therapy. Antimicrob Agents Chemother. 2010;54:3551-6.

22. Harris PN, Tambyah PA, Paterson DL. $\beta$-lactam and $\beta$-lactamase inhibitor combinations in the treatment of extended-spectrum $\beta$-lactamase producing Enterobacteriaceae: time for a reappraisal in the era of few antibiotic options? Lancet Infect Dis. 2015;15:475-85.

23. Roberts JA, Roberts MS, Robertson TA, Dalley AJ, Lipman J. Piperacillin penetration into tissue of critically ill patients with sepsis — bolus versus continuous administration? Crit Care Med. 2009:37:926-33.

24. Dulhunty JM, Roberts JA, Davis JS, Webb SAR, Bellomo R, Gomersall C, et al. Continuous infusion of beta-lactam antibiotics in severe sepsis: a multicenter double-blind, randomized controlled trial. Clin Infect Dis Off Publ Infect Dis Soc Am. 2013;56:236-44.

25. Roberts JA, Kirkpatrick CMJ, Roberts MS, Robertson TA, Dalley AJ, Lipman J. Meropenem dosing in critically ill patients with sepsis and without renal dysfunction: intermittent bolus versus continuous administration? Monte Carlo dosing simulations and subcutaneous tissue distribution. J Antimicrob Chemother. 2009:64:142-50.

26. Carlier M, Noë M, De Waele JJ, Stove V, Verstraete AG, Lipman J, et al. Population pharmacokinetics and dosing simulations of amoxicillin/clavulanic acid in critically ill patients. J Antimicrob Chemother 2013;68:2600-8.

27. Wu N, Chen BY, Tian SF, Chu YZ. The inoculum effect of antibiotics against CTX-M-extended-spectrum $\beta$-lactamase-producing Escherichia coli. Ann Clin Microbiol Antimicrob. 2014;13:45.

28. Lob SH, Nicolle LE, Hoban DJ, Kazmierczak KM, Badal RE, Sahm DF. Susceptibility patterns and ESBL rates of Escherichia coli from urinary tract infections in Canada and the United States, SMART 2010-2014. Diagn Microbiol Infect Dis. 2016;85:459-65.

29. Jean S-S, Coombs G, Ling T, Balaji V, Rodrigues C, Mikamo H, et al. Epidemiology and antimicrobial susceptibility profiles of pathogens causing urinary tract infections in the Asia-Pacific region: results from the Study for Monitoring Antimicrobial Resistance Trends (SMART), 2010-2013. Int J Antimicrob Agents. 2016;47:328-34.

30. Sader HS, Farrell DJ, Flamm RK, Jones RN. Antimicrobial susceptibility of gram-negative organisms isolated from patients hospitalised with pneumonia in US and European hospitals: results from the SENTRY Antimicrobial Surveillance Program, 2009-2012. Int J Antimicrob Agents. 2014;43:328-34.

31. Lodise TP, Lomaestro B, Drusano GL. Piperacillin-tazobactam for Pseudomonas aeruginosa infection: clinical implications of an extendedinfusion dosing strategy. Clin Infect Dis Off Publ Infect Dis Soc Am. 2007;44:357-63.
32. Roberts JA, Ulldemolins M, Roberts MS, McWhinney B, Ungerer J, Paterson DL, et al. Therapeutic drug monitoring of $\beta$-lactams in critically ill patients: proof of concept. Int J Antimicrob Agents. 2010;36:332-9.

33. Sturm AW, Allen N, Rafferty KD, Fish DN, Toschlog E, Newell M, et al. Pharmacokinetic analysis of piperacillin administered with tazobactam in critically ill, morbidly obese surgical patients. Pharmacotherapy. 2014;34:28-35.

34. De Waele JJ, De Neve N. Aminoglycosides for life-threatening infections: a plea for an individualized approach using intensive therapeutic drug monitoring. Minerva Anestesiol. 2014;80:1135-42.

35. De Waele JJ, Carrette S, Carlier M, Stove V, Boelens J, Claeys G, et al. Therapeutic drug monitoring-based dose optimisation of piperacillin and meropenem: a randomised controlled trial. Intensive Care Med. 2014;40:380-7.

36. Felton TW, McCalman K, Malagon I, Isalska B, Whalley S, Goodwin J, et al. Pulmonary penetration of piperacillin and tazobactam in critically ill patients. Clin Pharmacol Ther. 2014;96:438-48.

37. McKinnon PS, Paladino JA, Schentag JJ. Evaluation of area under the inhibitory curve (AUIC) and time above the minimum inhibitory concentration ( $\mathrm{T}>\mathrm{MIC}$ ) as predictors of outcome for cefepime and ceftazidime in serious bacterial infections. Int J Antimicrob Agents. 2008:31:345-51.

38. Sádaba B, Azanza JR, Campanero MA, García-Quetglas E. Relationship between pharmacokinetics and pharmacodynamics of beta-lactams and outcome. Clin Microbiol Infect Off Publ Eur Soc Clin Microbiol Infect Dis. 2004;10:990-8.

39. Felton TW, Roberts JA, Lodise TP, Van Guilder M, Boselli E, Neely MN, et al. Individualization of piperacillin dosing for critically ill patients: dosing software to optimize antimicrobial therapy. Antimicrob Agents Chemother. 2014;58:4094-102.

40. Abdul-Aziz MH, Lipman J, Akova M, Bassetti M, De Waele JJ, Dimopoulos $\mathrm{G}$, et al. Is prolonged infusion of piperacillin/tazobactam and meropenem in critically ill patients associated with improved pharmacokinetic/pharmacodynamic and patient outcomes? An observation from the Defining antibiotic levels in intensive care unit patients (DALI) cohort. J Antimicrob Chemother. 2016;71:196-207.

41. Ulldemolins M, Martín-Loeches I, Llauradó-Serra M, Fernández J, Vaquer S, Rodríguez A, et al. Piperacillin population pharmacokinetics in critically ill patients with multiple organ dysfunction syndrome receiving continuous venovenous haemodiafiltration: effect of type of dialysis membrane on dosing requirements. J Antimicrob Chemother. 2016;71:1651-9.

42. Shotwell MS, Nesbitt R, Madonia PN, Gould ER, Connor MJ, Salem C, et al. Pharmacokinetics and pharmacodynamics of extended infusion versus short infusion piperacillin-tazobactam in critically ill patients undergoing CRRT. CJASN. 2016;11:1377-83.

43. Connor MJ, Salem C, Bauer SR, Hofmann CL, Groszek J, Butler R, et al. Therapeutic drug monitoring of piperacillin-tazobactam using spent dialysate effluent in patients receiving continuous venovenous hemodialysis. Antimicrob Agents Chemother. 2011;55:557-60.

44. Thompson MI, Russo ME, Matsen JM, Atkin-Thor E. Piperacillin pharmacokinetics in subjects with chronic renal failure. Antimicrob Agents Chemother. 1981;19:450-3.

45. Giron JA, Meyers BR, Hirschman SZ, Srulevitch E. Pharmacokinetics of piperacillin in patients with moderate renal failure and in patients undergoing hemodialysis. Antimicrob Agents Chemother. 1981;19:279-83.

46. Francke EL, Appel GB, Neu HC. Pharmacokinetics of intravenous piperacillin in patients undergoing chronic hemodialysis. Antimicrob Agents Chemother. 1979;16:788-91.

47. Guet-Revillet H, Emirian A, Groh M, Nebbad-Lechani B, Weiss E, JoinLambert $\mathrm{O}$, et al. Pharmacological study of cefoxitin as an alternative antibiotic therapy to carbapenems in treatment of urinary tract infections due to extended-spectrum- $\beta$-lactamase-producing Escherichia coli. Antimicrob Agents Chemother. 2014;58:4899-901.

48. Vincent J-L, Bassetti M, François B, Karam G, Chastre J, Torres A, et al. Advances in antibiotic therapy in the critically ill. Crit Care Lond Engl. 2016;20:133.

49. Laterre P-F, Wittebole X, Van de Velde S, Muller AE, Mouton JW, Carryn $S$, et al. Temocillin ( $6 \mathrm{~g}$ daily) in critically ill patients: continuous infusion 
versus three times daily administration. J Antimicrob Chemother. 2015;70:891-8.

50. Chopra T, Marchaim D, Veltman J, Johnson P, Zhao JJ, Tansek R, et al. Impact of cefepime therapy on mortality among patients with bloodstream infections caused by extended-spectrum- $\beta$-lactamaseproducing Klebsiella pneumoniae and Escherichia coli. Antimicrob Agents Chemother. 2012;56:3936-42.

51. Gutiérrez-Gutiérrez B, Pérez-Galera S, Salamanca E, de Cueto M, Calbo E, Almirante B, et al. $\beta$-lactam/ $\beta$-lactamase inhibitor combinations for the treatment of bloodstream infections due to extended-spectrum $\beta$-lactamase-producing enterobacteriaceae: a multinational, pre-registered cohort study. Antimicrob Agents Chemother. 2016;11:AAC-00365.

52. Apisarnthanarak A, Kiratisin P, Mundy LM. Predictors of mortality from community-onset bloodstream infections due to extended-spectrum beta-lactamase-producing Escherichia coli and Klebsiella pneumoniae. Infect Control Hosp Epidemiol. 2008;29:671-4.

53. Lee C-H, Su L-H, Tang Y-F, Liu J-W. Treatment of ESBL-producing Klebsiella pneumoniae bacteraemia with carbapenems or flomoxef: a retrospective study and laboratory analysis of the isolates. J Antimicrob Chemother. 2006;58:1074-7.

54. Lee N-Y, Lee C-C, Huang W-H, Tsui K-C, Hsueh P-R, Ko W-C. Cefepime therapy for monomicrobial bacteremia caused by cefepime-susceptible extended-spectrum beta-lactamase-producing enterobacteriaceae: MIC matters. Clin Infect Dis Off Publ Infect Dis Soc Am. 2013;56:488-95.

55. Paterson DL, Ko W-C, Von Gottberg A, Mohapatra S, Casellas JM, Goossens $\mathrm{H}$, et al. Antibiotic therapy for Klebsiella pneumoniae bacteremia: implications of production of extended-spectrum beta-lactamases. Clin Infect Dis Off Publ Infect Dis Soc Am. 2004;39:31-7.

56. Nord CE, Heimdahl A, Kager L, Malmborg AS. The impact of different antimicrobial agents on the normal gastrointestinal microflora of humans. Rev Infect Dis. 1984;6(Suppl 1):S270-5.

57. Perez F, Pultz MJ, Endimiani A, Bonomo RA, Donskey CJ. Effect of antibiotic treatment on establishment and elimination of intestinal colonization by KPC-producing Klebsiella pneumoniae in mice. Antimicrob Agents Chemother. 2011;55:2585-9.

58. Efe Iris N, Sayıner H, Yildirmak T, Simsek F, Arat ME. Vancomycin-resistant Enterococcus carrier status in the reanimation units and related risk factors. Am J Infect Control. 2013;41:261-2.

59. Donskey CJ. Antibiotic regimens and intestinal colonization with antibiotic-resistant gram-negative bacilli. Clin Infect Dis Off Publ Infect Dis Soc Am. 2006;43(Suppl 2):S62-9.

60. Gasink LB, Edelstein PH, Lautenbach E, Synnestvedt M, Fishman NO Risk factors and clinical impact of Klebsiella pneumoniae carbapenemase-producing K. pneumoniae. Infect Control Hosp Epidemiol. 2009;30:1180-5.

61. Schwaber MJ, Klarfeld-Lidji S, Navon-Venezia S, Schwartz D, Leavitt A, Carmeli Y. Predictors of carbapenem-resistant Klebsiella pneumoniae acquisition among hospitalized adults and effect of acquisition on mortality. Antimicrob Agents Chemother. 2008;52:1028-33.

62. Wang Q, Zhang Y, Yao X, Xian H, Liu Y, Li H, et al. Risk factors and clinical outcomes for carbapenem-resistant Enterobacteriaceae nosocomial infections. Eur J Clin Microbiol Infect Dis Off Publ Eur Soc Clin Microbiol. 2016;35:1679-89.

63. Falagas ME, Rafailidis PI, Kofteridis D, Virtzili S, Chelvatzoglou FC, Papaioannou V, et al. Risk factors of carbapenem-resistant Klebsiella pneumoniae infections: a matched case control study. J Antimicrob Chemother. 2007:60:1124-30.

64. Papadimitriou-Olivgeris M, Marangos M, Fligou F, Christofidou M, Bartzavali C, Anastassiou ED, et al. Risk factors for KPC-producing Klebsiella pneumoniae enteric colonization upon ICU admission. J Antimicrob Chemother. 2012;67:2976-81.

65. Stiefel U, Pultz NJ, Donskey CJ. Effect of carbapenem administration on establishment of intestinal colonization by vancomycin-resistant enterococci and Klebsiella pneumoniae in mice. Antimicrob Agents Chemother. 2007;51:372-5.

66. Antimicrobial resistance interactive database (EARS-Net) [cited 2016 Sep 20]. http://ecdc.europa.eu/en/healthtopics/antimicrobial-resistance-and-consumption/antimicrobial_resistance/database/Pages/ table_reports.aspx.
67. Li H, Estabrook M, Jacoby GA, Nichols WW, Testa RT, Bush K. In vitro susceptibility of characterized $\beta$-lactamase-Producing strains tested with avibactam combinations. Antimicrob Agents Chemother. 2015;59:1789-93.

68. Drawz SM, Bonomo RA. Three decades of beta-lactamase inhibitors. Clin Microbiol Rev. 2010;23:160-201.

69. Kang C-I, Park SY, Chung DR, Peck KR, Song J-H. Piperacillin-tazobactam as an initial empirical therapy of bacteremia caused by extended-spectrum $\beta$-lactamase-producing Escherichia coli and Klebsiella pneumoniae. J Infect. 2012;64:533-4.

70. Bloos F, Rüddel H, Thomas-Rüddel D, Schwarzkopf D, Pausch C, Harbarth S, et al. Effect of a multifaceted educational intervention for anti-infectious measures on sepsis mortality: a cluster randomized trial. Intensive Care Med. 2017. http://doi.org/10.1007/s00134-017-4782-4

71. Guet-Revillet $H$, Tomini E, Emirian A, Join-Lambert O, Lécuyer $H$, Zahar J-R, et al. Piperacillin/tazobactam as an alternative antibiotic therapy to carbapenems in the treatment of urinary tract infections due to extended-spectrum $\beta$-lactamase-producing enterobacteriaceae: an in silico pharmacokinetic study. Int. J. Antimicrob Agents. 2016;49:62-6.

72. Roberts JA, Abdul-Aziz MH, Lipman J, Mouton JW, Vinks AA, Felton TW, et al. Individualised antibiotic dosing for patients who are critically ill: challenges and potential solutions. Lancet Infect Dis. 2014;14:498-509.

73. Pettigrew MM, Johnson JK, Harris AD. The human microbiota: novel targets for hospital-acquired infections and antibiotic resistance. Ann Epidemiol. 2016;26:342-7.

74. Gharbi M, Moore LSP, Gilchrist M, Thomas CP, Bamford K, Brannigan ET, et al. Forecasting carbapenem resistance from antimicrobial consumption surveillance: lessons learnt from an OXA-48-producing Klebsiella pneumoniae outbreak in a West London renal unit. Int J Antimicrob Agents. 2015;46:150-6.

75. Plüss-Suard C, Pannatier A, Kronenberg A, Mühlemann K, Zanetti G. Impact of antibiotic use on carbapenem resistance in Pseudomonas aeruginosa: is there a role for antibiotic diversity? Antimicrob Agents Chemother. 2013;57:1709-13.

76. Wexler HM, Finegold SM. Impact of imipenem/cilastatin therapy on normal fecal flora. Am J Med. 1985;78:41-6.

77. DiNubile MJ, Chow JW, Satishchandran V, Polis A, Motyl MR, Abramson MA, et al. Acquisition of resistant bowel flora during a double-blind randomized clinical trial of ertapenem versus piperacillin-tazobactam therapy for intraabdominal infections. Antimicrob Agents Chemother. 2005;49:3217-21.

78. Pultz MJ, Donskey CJ. Effects of imipenem-cilastatin, ertapenem, piperacillin-tazobactam, and ceftriaxone treatments on persistence of intestinal colonization by extended-spectrum-beta-lactamaseproducing Klebsiella pneumoniae strains in mice. Antimicrob Agents Chemother. 2007;51:3044-5.

79. Gagliotti C, Giordani S, Ciccarese V, Barozzi A, Giovinazzi A, Pietrantonio AM, et al. Risk factors for colonization with carbapenemase-producing Klebsiella pneumoniae in hospital: a matched case-control study. Am J Infect Control. 2014;42:1006-8.

80. Mittal G, Gaind R, Kumar D, Kaushik G, Gupta KB, Verma PK, et al. Risk factors for fecal carriage of carbapenemase producing enterobacteriaceae among intensive care unit patients from a tertiary care center in India. BMC Microbiol. 2016;16:138.

81. Ling ML, Tee YM, Tan SG, Amin IM, How KB, Tan KY, et al. Risk factors for acquisition of carbapenem resistant enterobacteriaceae in an acute tertiary care hospital in Singapore. Antimicrob Resist Infect Control. 2015;4:26.

82. Jiao Y, Qin Y, Liu J, Li Q, Dong Y, Shang Y, et al. Risk factors for carbapenem-resistant Klebsiella pneumoniae infection/colonization and predictors of mortality: a retrospective study. Pathog Glob Health. 2015;109:68-74.

83. Candevir Ulu A, Kurtaran B, Inal AS, Kömür S, Kibar F, Yapııı Çiçekdemir $\mathrm{H}$, et al. Risk factors of carbapenem-resistant Klebsiella pneumoniae infection: a serious threat in ICUs. Med Sci Monit Int Med J Exp Clin Res. 2015;21:219-24.

84. Gómez Rueda V, Zuleta Tobón JJ. Risk factors for infection with carbapenem-resistant Klebsiella pneumoniae: a case-case-control study. Colomb Méd Cali Colomb. 2014;45:54-60. 
85. Ahn JY, Song JE, Kim MH, Choi H, Kim JK, Ann HW, et al. Risk factors for the acquisition of carbapenem-resistant Escherichia coli at a tertiary care center in South Korea: a matched case-control study. Am J Infect Control. 2014;42:621-5.

86. Mantzarlis K, Makris D, Manoulakas E, Karvouniaris M, Zakynthinos E. Risk factors for the first episode of Klebsiella pneumoniae resistant to carbapenems infection in critically ill patients: a prospective study. Biomed Res Int. 2013;2013:850547.

87. Dizbay M, Guzel Tunccan O, Karasahin O, Aktas F. Emergence of carbapenem-resistant Klebsiella spp infections in a Turkish university hospital: epidemiology and risk factors. J Infect Dev Ctries. 2014;8:44-9.

88. Orsi GB, Bencardino A, Vena A, Carattoli A, Venditti C, Falcone M, et al. Patient risk factors for outer membrane permeability and KPC-producing carbapenem-resistant Klebsiella pneumoniae isolation: results of a double case-control study. Infection. 2013;41:61-7.

89. Chang H-J, Hsu P-C, Yang C-C, Kuo A-J, Chia J-H, Wu T-L, et al. Risk factors and outcomes of carbapenem-nonsusceptible Escherichia coli bacteremia: a matched case-control study. J Microbiol Immunol Infect Wei Mian Yu Gan Ran Za Zhi. 2011;44:125-30.

90. Tuon FF, Rocha JL, Toledo P, Arend LN, Dias CH, Leite TM, et al. Risk factors for KPC-producing Klebsiella pneumoniae bacteremia. Braz J Infect Dis Off Publ Braz Soclnfect Dis. 2012;16:416-9.

91. Papadimitriou-Olivgeris M, Marangos M, Christofidou M, Fligou F, Bartzavali C, Panteli ES, et al. Risk factors for infection and predictors of mortality among patients with KPC-producing Klebsiella pneumoniae bloodstream infections in the intensive care unit. Scand J Infect Dis. 2014;46:642-8.

92. Maseda E, Salgado P, Anillo V, Ruiz-Carrascoso G, Gómez-Gil R, MartínFunke C, et al. Risk factors for colonization by carbapenemase-producing enterobacteria at admission to a Surgical ICU: a retrospective study. Clin: Enferm Infecc Microbiol; 2016.

93. Popejoy MW, Paterson DL, Cloutier D, Huntington JA, Miller B, Bliss CA, et al. Efficacy of ceftolozane/tazobactam against urinary tract and intra-abdominal infections caused by ESBL-producing Escherichia coli and Klebsiella pneumoniae: a pooled analysis of Phase 3 clinical trials. J Antimicrob Chemother. 2017;72:268-72.

94. Balakrishnan I, Awad-El-Kariem FM, Aali A, Kumari P, Mulla R, Tan B, et al. Temocillin use in England: clinical and microbiological efficacies in infections caused by extended-spectrum and/or derepressed AmpC $\beta$-lactamase-producing Enterobacteriaceae. J Antimicrob Chemother. 2011;66:2628-31.

95. Bin C, Hui W, Renyuan Z, Yongzhong N, Xiuli X, Yingchun X, et al. Outcome of cephalosporin treatment of bacteremia due to CTX-M-type extended-spectrum beta-lactamase-producing Escherichia coli. Diagn Microbiol Infect Dis. 2006;56:351-7.

96. Chaubey VP, Pitout JD, Dalton B, Ross T, Church DL, Gregson DB, et al. Clinical outcome of empiric antimicrobial therapy of bacteremia due to extended-spectrum beta-lactamase producing Escherichia coli and Klebsiella pneumoniae. BMC Res Notes. 2010;3:116.

97. Chung H-C, Lai C-H, Lin J-N, Huang C-K, Liang S-H, Chen W-F, et al. Bacteremia caused by extended-spectrum- $\beta$-lactamase-producing Escherichia coli sequence type ST131 and non-ST131 clones: comparison of demographic data, clinical features, and mortality. Antimicrob Agents Chemother. 2012;56:618-22.

98. De Rosa FG, Pagani N, Fossati L, Raviolo S, Cometto C, Cavallerio P, et al. The effect of inappropriate therapy on bacteremia by ESBL-producing bacteria. Infection. 2011;39:555-61.

99. Endimiani A, Luzzaro F, Brigante G, Perilli M, Lombardi G, Amicosante $\mathrm{G}$, et al. Proteus mirabilis bloodstream infections: risk factors and treatment outcome related to the expression of extended-spectrum beta-lactamases. Antimicrob Agents Chemother. 2005;49:2598-605.

100. Ferrández O, Grau S, Saballs P, Luque S, Terradas R, Salas E. Mortality risk factors for bloodstream infections caused by extended-spectrum betalactamase-producing microorganisms. Rev Clín Esp. 2011;211:119-26.
101. Gudiol C, Calatayud L, Garcia-Vidal C, Lora-Tamayo J, Cisnal M, Duarte R, et al. Bacteraemia due to extended-spectrum beta-lactamase-producing Escherichia coli (ESBL-EC) in cancer patients: clinical features, risk factors, molecular epidemiology and outcome. J Antimicrob Chemother. 2010;65:333-41.

102. Harris PNA, Yin M, Jureen R, Chew J, Ali J, Paynter S, et al. Comparable outcomes for $\beta$-lactam/ $\beta$-lactamase inhibitor combinations and carbapenems in definitive treatment of bloodstream infections caused by cefotaxime-resistant Escherichia coli or Klebsiella pneumoniae. Antimicrob Resist Infect Control. 2015;4:14.

103. Lee $\mathrm{C}-\mathrm{H}$, Lee $\mathrm{Y}-\mathrm{T}$, Kung $\mathrm{C}-\mathrm{H}, \mathrm{Ku}$ W-W, Kuo S-C, Chen T-L, et al. Risk factors of community-onset urinary tract infections caused by plasmid-mediated AmpC $\beta$-lactamase-producing Enterobacteriaceae. J Microbiol Immunol Infect. 2015;48:269-75.

104. Matsumura Y, Yamamoto M, Nagao M, Komori T, Fujita N, Hayashi A, et al. Multicenter retrospective study of cefmetazole and flomoxef for treatment of extended-spectrum- $\beta$-lactamase-producing Escherichia coli bacteremia. Antimicrob Agents Chemother. 2015;59:5107-13.

105. Qureshi ZA, Paterson DL, Pakstis DL, Adams-Haduch JM, Sandkovsky

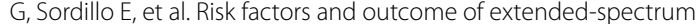
$\beta$-lactamase-producing Enterobacter cloacae bloodstream infections. Int J Antimicrob Agents. 2011;37:26-32.

106. Pilmis B, Parize P, Zahar JR, Lortholary O. Alternatives to carbapenems for infections caused by ESBL-producing enterobacteriaceae. Microbiol: Eur J Clin Microbiol Infect Dis Off Publ Eur Soc Clin; 2014.

107. Retamar P, López-Cerero L, Muniain MA, Pascual Á, Rodríguez-Baño J, ESBL-REIPI/GEIH Group. Impact of the MIC of piperacillin-tazobactam on the outcome of patients with bacteremia due to extendedspectrum- $\beta$-lactamase-producing Escherichia coli. Antimicrob Agents Chemother. 2013;57:3402-4.

108. Tsai H-Y, Chen Y-H, Tang H-J, Huang C-C, Liao C-H, Chu F-Y, et al. Carbapenems and piperacillin/tazobactam for the treatment of bacteremia caused by extended-spectrum $\beta$-lactamase-producing Proteus mirabilis. Diagn Microbiol Infect Dis. 2014;80:222-6.

109. Tumbarello M, Sanguinetti M, Montuori E, Trecarichi EM, Posteraro B, Fiori B, et al. Predictors of mortality in patients with bloodstream infections caused by extended-spectrum-beta-lactamase-producing Enterobacteriaceae: importance of inadequate initial antimicrobial treatment. Antimicrob Agents Chemother. 2007;51:1987-94.

110. Tuon FF, Bianchet LC, Penteado-Filho SR. Epidemiology of extended spectrum beta-lactamase producing enterobacter bacteremia in a brazilian hospital. Rev Soc Bras Med Trop. 2010;43:452-4.

111. van Duin D, Bonomo RA. Ceftazidime/avibactam and ceftolozane/tazobactam: second-generation $\beta$-lactam/ $\beta$-lactamase inhibitor combinations. Clin Infect Dis Off Publ Infect Dis Soc Am. 2016;63:234-41.

\section{Submit your manuscript to a SpringerOpen ${ }^{\odot}$ journal and benefit from:}

- Convenient online submission

- Rigorous peer review

- Open access: articles freely available online

- High visibility within the field

- Retaining the copyright to your article

Submit your next manuscript at springeropen.com 